\title{
No increase in primary nosocomial candidemia in 682 German intensive care units during 2006 to 2011
}

E Meyer (elisabeth.meyer@charite.de)1,2, C Geffers ${ }^{1,2}$, P Gastmeier ${ }^{1,2}$, F Schwab ${ }^{1,2}$

1. Institute of Hygiene and Environmental Medicine, Charité University Medicine Berlin, Berlin, Germany

2. National Reference Centre for Surveillance of Nosocomial Infections, Berlin, Germanyn

Meyer E, Geffers C, Gastmeier P, Schwab F. No increase in primary nosocomial candidemia in 682 German intensive care units during 2006 to 2011 . Euro Surveill. 2013;18(24): pii=20505. Available online: http://www.eurosurveillance.org/ViewArticle.aspx?Articleld=20505

We evaluated the epidemiology of and trends in primary nosocomial candidemia within a network of 682 German intensive care units (ICUs) during 2006 to 2011. Nosocomial laboratory-confirmed bloodstream infection (NLCBI) was diagnosed using standard definitions from the United States Centers for Disease Control and Prevention. Incidences were calculated by NLCBI per 1,000 patients and incidence densities per 1,000 patient-days and per 1,000 central-line days. In the 682 ICUs, there were $2,220,803$ patients, $7,943,615$ patient-days and 5,363,026 central-line days. A total of 381 of the 6,666 NLCBIs were associated with Candida albicans, 142 with non-albicans Candida. Non-albicans Candida made up $26 \%$ of all the Candida isolates. The mean incidence density of Candida central line-associated NLCBIs was 0.09 per 1,000 central-line days and remained unchanged between 2006 and 2011. Crude ICU mortality was $\mathbf{2 1 . 9} \%$ for $C$. albicans and $29.7 \%$ for non-albicans Candida. Candida was the fourth leading cause of primary NLCBIs, accounting for $6.5 \%$ of all bloodstream infections acquired in ICUs. Based on an incidence density of 0.07 per 1,000 patient-days, extrapolation of our data resulted in 465 primary nosocomial Candida NLCBIs in German ICUs per year. Our data show that there was no increase in primary Candida NLCBIs during 2006 to 2011.

\section{Introduction}

Candida species are frequently isolated in nosocomial bloodstream infections [1]. Depending on the geographical region, Candida is the third to the tenth most commonly isolated pathogen in blood cultures [2-4].

Candida spp. are common inhabitants of the mucosal surfaces in the tracheal, gastrointestinal and genitourinary tracts. In most cases, candidemia is deemed to arise endogenously, preceded by colonisation with the infecting strain [5]. Patients in an intensive care unit (ICU) are at particular risk for candidemia because of their debilitated condition, presence of central lines and the fact they are often subject to renal dialysis or receipt of broad-spectrum antibiotics or parenteral nutrition [6].
Bloodstream infections can be either primary or secondary [7]. Most primary infections are due to colonised intravascular catheters. Colonisation occurs from bacteria embedded in a biofilm matrix, originating mostly from a patient's skin microflora.

Secondary infections are disseminated from infections acquired at other sites, such as the peritoneum, urinary tract, lung, postoperative wounds and skin.

The mortality rate of infected persons due to candidemia varies considerably, from $20 \%$ to $60 \%$ [8-11]. The prognosis is better for primary than for secondary candidemia [7]. Expanded use of antifungals has probably influenced the temporal trends of primary and secondary candidemia, as has the species causing candidemia $[3,12]$.

Antifungals are widely advertised and prescribed for therapy and prophylaxis. The pharmaceutical industry valued the global market for human antifungal therapeutics at USD 9.8 billion (EUR 7.6 billion) in 2009 and expected it to increase at a compound annual growth rate of approximately $3.8 \%$ to reach USD 11.3 billion (EUR 8.8 billion) in 2014 [13].

In Germany, hospitals are obliged to collect and analyse data on nosocomial infections and drug-resistant pathogens [14]. These routine data are reported to the National Reference Centre for the Surveillance of Nosocomial Infections.

The aim of our study was to evaluate the epidemiology of and analyse the trends in primary nosocomial candidemia within a network of 682 German ICUs between 2006 and 2011.

\section{Methods}

\section{Study population}

The Krankenhaus Infektions Surveillance System is a voluntary, web-based national surveillance system for nosocomial infections in Germany, to which about a quarter of all German ICUs report data [15]. From 
January 2006 to December 2011, all ICU patients who developed nosocomial laboratory-confirmed bloodstream infections (NLCBIs) were included in our study. A total of 682 ICUs reported the type of ICU, and size and type of hospital. Of these, 365 ICUs were interdisciplinary, 119 surgical, 109 medical, 17 neurosurgical, 17 paediatric, 16 cardiac surgical, 10 neurological and 29 other ICUs.

For every patient with an NLCBI, the time from admission to the ICU to time of onset of infection is reported, as is sex, age, central-line use within 48 hours before the infection, type of pathogen (up to four pathogens) and mortality. The onset of infection is defined as either the onset of the first clinical symptom or the day the samples were taken for microbiology cultures that led to diagnosis of the infection. The earlier date is defined as the onset of infection. All ICUs also report the number of central central-line days and patient days.

ICUs report only primary NLCBIs [16].

NLCBIs were defined as central-line associated if a central line was in place at the time of, or within 48 hours before, the onset of the infection.

Fungal pathogens were reported as C. albicans, nonalbicans spp., Aspergillus spp. or other fungi and could be isolated in a blood culture as the only pathogen (monomicrobial case) or as one of several pathogens (polymicrobial case).

As the frequency of NLCBIs might be biased because of different types of ICUs, the type of hospital and, most importantly, by the frequency of microbiological diagnostics (blood cultures) we analysed changes over time for all ICUs and also for a subgroup of ICUs that participated continuously over the six years.

\section{Definition of nosocomial primary candidemia} The Krankenhaus Infektions Surveillance System uses the United States Centers for Disease Control and Prevention (CDC) standard definitions [16]. ICUs reported only primary NLCBIs [17]. Nosocomial primary candidemia was defined as occurring in an ICU patient without signs and symptoms of infection at the time of admission to the ICU, with one or more blood cultures positive for Candida, while candidemia was not related to Candida infection of another site.

\section{Statistics}

Incidence was calculated as the number of NLCBIs per 1,000 patients. Incidence density was calculated as the number of NLCBIs per 1000 patient days or per 1,000 central-line days. Time from ICU admission to onset of infection and crude ICU mortality was calculated for monomicrobial cases only.

All analyses were performed using SPSS (IBM SPSS statistics, Somer, NY, United States), SAS (SAS Institute,
Cary, NC, United States) and Epi Info 6 (CDC, Atlanta, GA, United States).

\section{Results}

From January 2006 to December 2011, 682 German ICUs submitted data to the Krankenhaus Infektions Surveillance System. A total of 2,220,803 patients were included, accounting for 7,943,615 patient days, $5,363,026$ central-line days and a median length of stay of 3.6 days (interquartile range (IQR): 2.8-5.0). ICUs submitted data for a median of 39 months (IQR: 18-64). The number of ICUs increased over time, from 347 in 2006 to 455 in 2009 and to 527 in 2011. A total of 205 ICUs submitted the data continuously from 2006 to 2011.

A total of 6,666 NLCBIs associated with 7,453 pathogens were reported. Among the 6,666 NLCBIs, 5,970 (90\%) were monomicrobial cases while the rest were polymicrobial (618 cases with two pathogens, 65 with three and 13 with four). A total of 6,382 (96\%) NLCBIs were central-line associated.

Fungi were isolated 575 times from 563 (8\%) of the NLCBIs. Of these 575 , a total $381(66 \%)$ were associated with C. albicans and 142 (25\%) with non-albicans Candida. Some 288 (76\%) of the cases with C. albicans infection were monomicrobial.

The mean incidence density of the NLCBIs stratified by pathogen type in 2006 to 2011 is shown (Figure 1). In $4,591(69 \%)$ of the NLCBIs, Gram-positive bacteria were reported, in 1,458 (22\%) Gram-negative bacteria and in $563(8 \%)$ fungi. If only monomicrobial NLCBIs $(n=5,960)$ were analysed, Gram-positive bacteria were the causative agent in 4,021 (67\%), Gram-negative bacteria in $1,109(19 \%)$ and fungi in $428(7 \%)$.

The mean incidence density of fungal NLCBIs per 1,000 patient days did not change significantly between 2006 and 2011 (0.09 (95\% Cl): 0.07-0.11) in 2006; 0.08 (95\% Cl: $0.07-0.10$ ) in 2011 (Figure 1).

The incidence of fungal NLCBIs per 1,000 patients also did not change significantly between 2006 and 2011. It was 0.30 in 2006 (95\% Cl: 0.24-0.37) and 0.29 in 2011 (95\% Cl: $0.24-0.35$ ).

With respect to candidemia, the mean incidence density of Candida spp. from 2006 to 2011 was 0.07 per 1,000 patient-days (Figure $2 \mathrm{~A}$ ) and of the central-line associated NCBLIs, it was 0.09 per 1,000 central-line days (Figure 2B).

The mean incidence density of Candida spp. revealed no significant difference over time. It was 0.08 per 1,000 patient-days in 2006 (95\% Cl: $0.06-0.10$ ) and 0.07 per 1,000 patient-days in 2011 (95\% Cl: $0.06-$ 0.09) (Figure 2A). 
Mean incidence density of all nosocomial primary laboratory-confirmed bloodstream infections $(n=6,666)$ and associated microorganisms $(n=7,453)$ in 682 intensive care units, Germany, 2006-2011

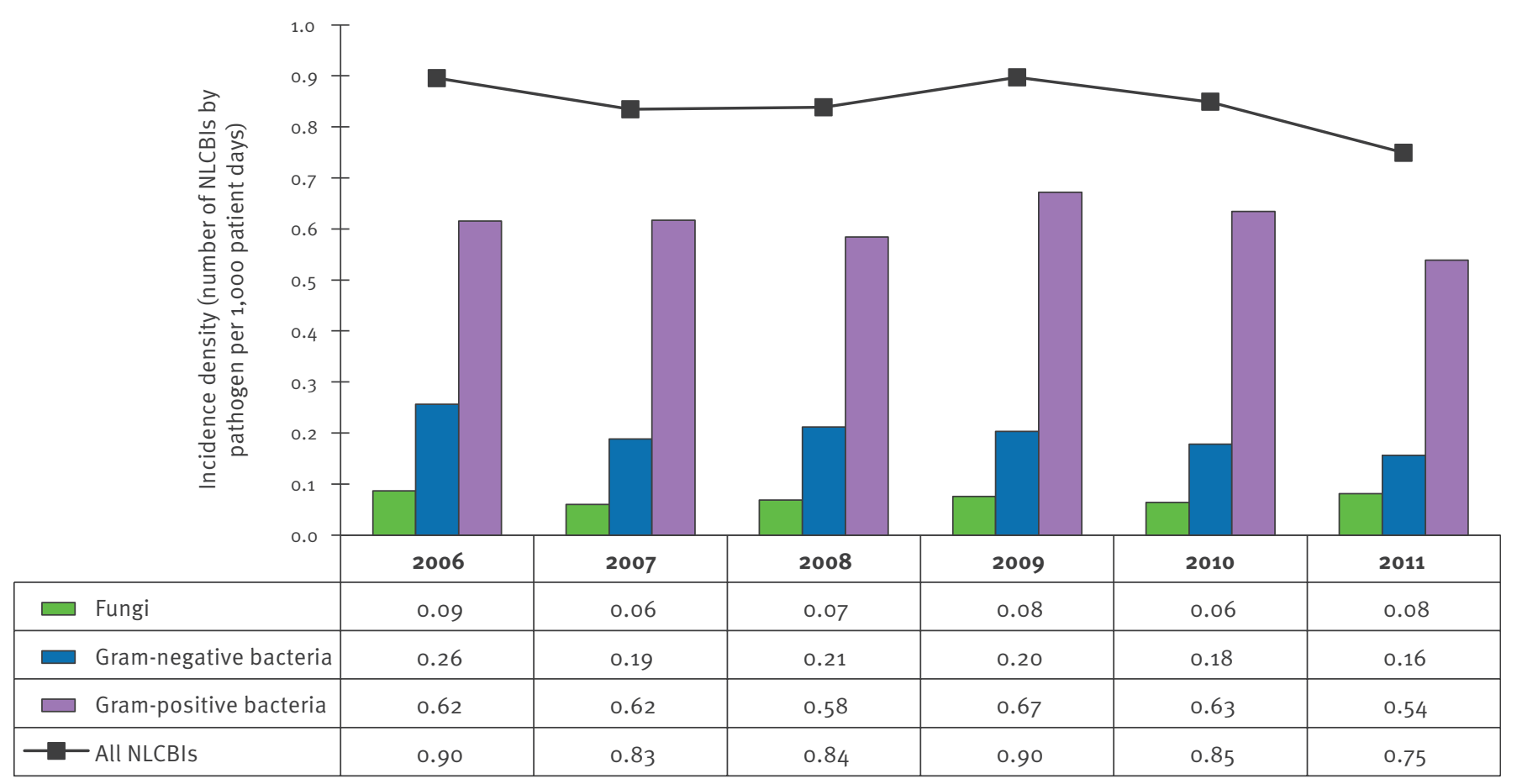

NLCBIs: nosocomial laboratory-confirmed bloodstream infections.

Gram-positive bacteria: Staphylococcus aureus, coagulase-negative staphylococci, Streptococcus pyogenes, Streptococcus pneumoniae, Enterococcus spp., Corynebacterium spp.

Gram-negative bacteria: Haemophilus spp., Escherichia coli, Klebsiella spp., Enterobacter spp., Citrobacter spp., Proteus spp., Serratia spp., other Enterobacteriacea, Pseudomonas aeruginosa, Burkholderia cepacia, Stenotrophomonas maltophilia, Acinetobacter spp., Bacteroides spp., Legionella spp.

Fungi: Candida albicans, non-albicans Candida spp., Aspergillus spp., other fungi.

The mean incidence density of NLCBIs with non-albicans Candida per 1,000 patient days was 0.02 in 2006 (95\% Cl: $0.01-0.03$ ) and 0.02 in 2011 (95\% Cl: $0.01-$ 0.03 ) and of Candida albicans 0.06 in 2006 (95\% Cl: $0.05-0.08)$ and 0.05 in 2011 (95\% Cl: 0.04-0.07).

If only ICUs with continuous participation over all six years were included in the analysis $(n=205)$, there was also no significant change over time in the Candida incidence in this subgroup analysis (data not shown).

For monomicrobial NLCBIs, the length of stay in the ICU before onset of infection differed, depending on the pathogen. The median time was generally shorter for Gram-positive pathogens (13-16 days) than for the Gram-negative pathogens Klebsiella spp. and Pseudomonas aeruginosa (18 and 19 days, respectively) and was 15 days for C. albicans (Figure 3).

C. albicans ranked fourth among the most frequently isolated pathogens in NLCBIs, after coagulase-negative staphylococci, Enterococcus spp. and Staphylococcus aureus. C. albicans accounted for $4.8 \%$ of all NLCBIs and all Candida spp. for $6.5 \%$ (Table 1). Non-albicans Candida made up $26 \%$ of all Candida spp. With respect to crude ICU mortality of NLCBIs Candida spp. took second place, with a mortality of $23.9 \%$ after $P$. aeruginosa with $24.5 \%$.

We extrapolated the data of our study of Candida NLCBIs: it resulted in 465 primary nosocomial Candida NLCBIs in German ICUs (based on an incidence density of 0.07 per 1,000 patient days and a total of $7,042,898$ ICU-patient days in 2008) [18,19].

The reported number of cases and incidence per 100,000 population of candidemia in countries with nationwide, coded-discharge diagnosis or a laboratory-based notification system (Denmark, Finland, Germany, and United States) is shown in Table 2.

\section{Discussion}

The most important finding of our multicentre study of German ICUs was that the mean incidence density 


\section{FIGURE 2}

Mean incidence density of the number nosocomial primary laboratory-confirmed bloodstream (NLCBIs) infections per 1,000 patient days (panel A) or central-line associated NLCBIs per 1,000 central-line days (panel B) with Candida albicans and non-albicans Candida $a^{\mathrm{a}}$ species in 682 intensive care units, Germany, 2006-2011

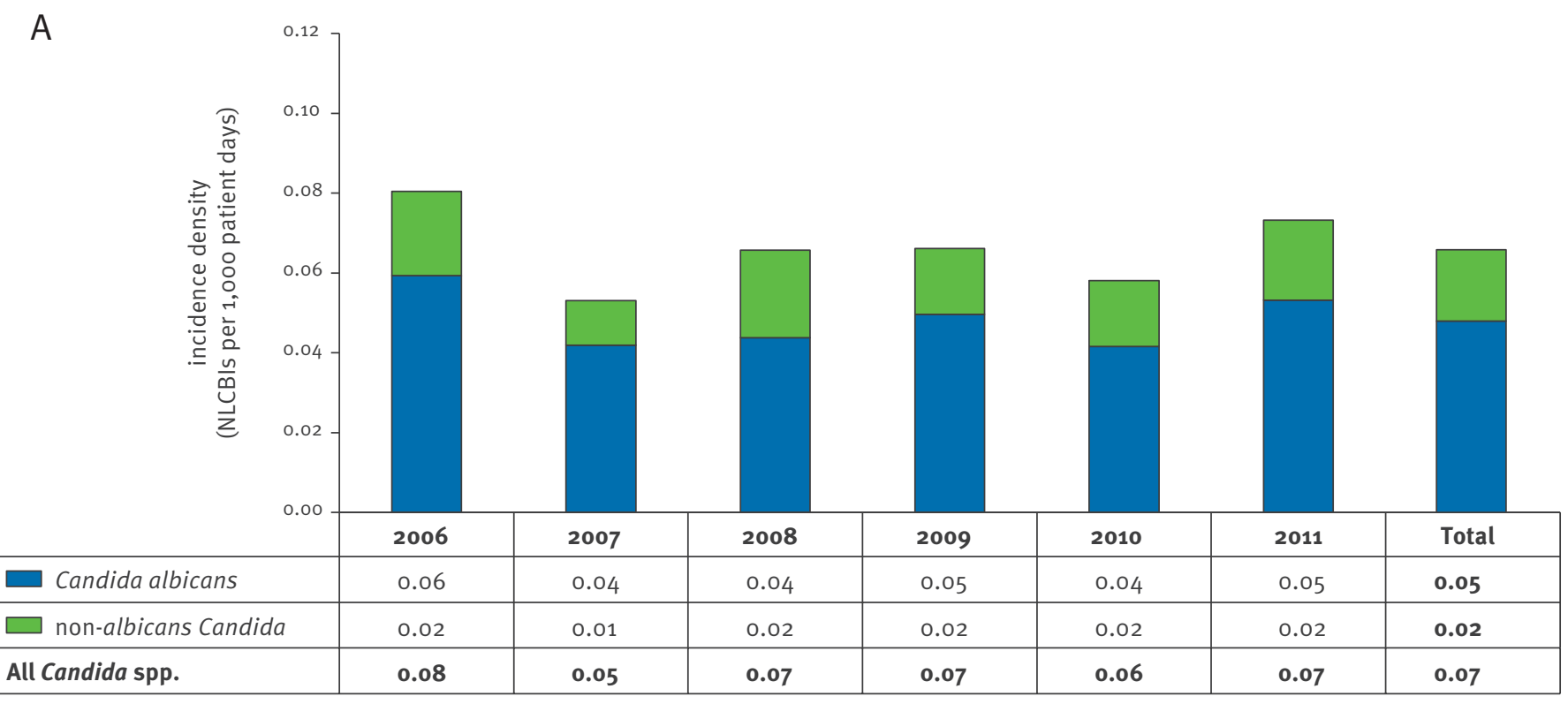

B

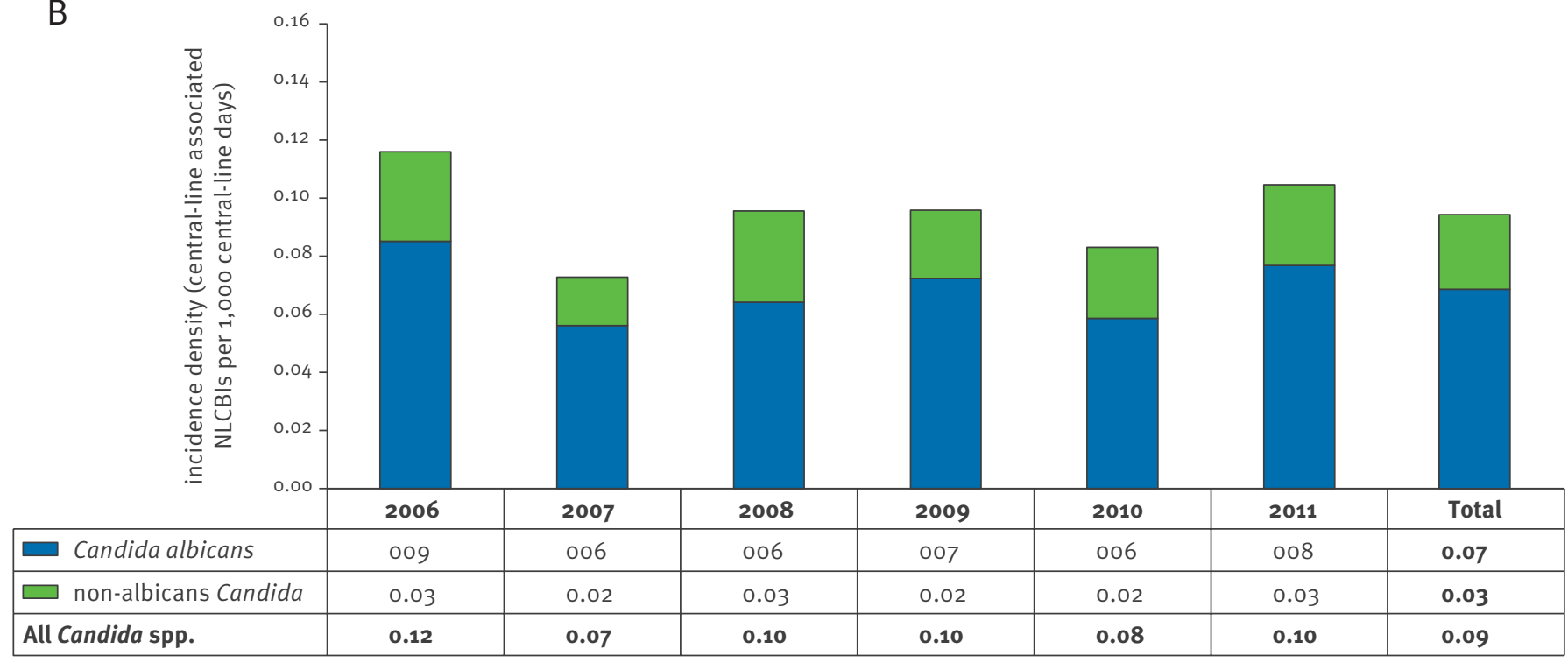

Note: numbers may not sum up because of rounding to the second decimal place.

${ }^{a}$ Mono- and polymicrobial cases. 


\section{FIGURE 3}

Interval between date of admission to the intensive care unit (ICU) and onset of infection of the most frequently isolated pathogens in monomicrobial nosocomial

laboratory-confirmed primary bloodstream infections in 682 ICUs, Germany, 2006-2011

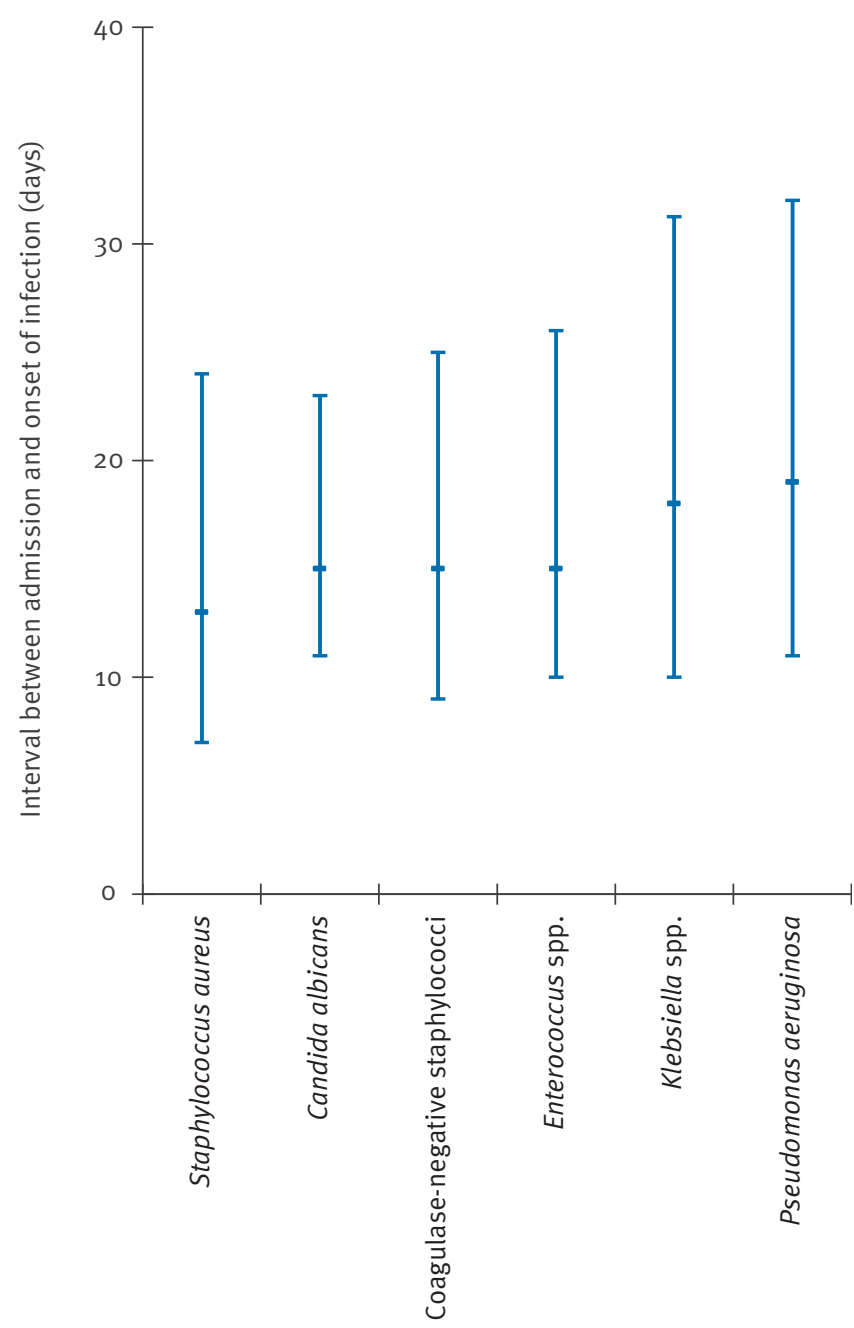

The median and interquartile range are depicted.

of Candida spp. central line-associated bloodstream infections was 0.09 per 1,000 central-line days from 2006 to 2011 and remained unchanged during this time. Furthermore, $C$. albicans was the fourth leading cause of primary NLCBIs in 682 German ICUs, accounting for $4.8 \%$ of all bloodstream infections acquired in the ICUs and it remains an important infection.

Data from the European Centre for Disease Prevention and Control (ECDC) reported that of the most frequently isolated microorganisms in ICU-acquired bloodstream infections in 11 European countries, the proportion of Candida spp. was $6.3 \%$ in 2004 , which increased to $7.5 \%$ in 2006 and decreased again to $6.3 \%$ in 2008 [20].
Data from 1,116 ICUs reporting to the United States National Nosocomial Infection Surveillance System showed that the incidence density of NLCBIs due to Candida decreased significantly from more than 0.9 NLCBI per 1,000 central-line days in 1989 to about 0.35 per 1,000 central-line days in 1999 [21]. Data from 2006 to 2007 reported 0.6 NLCBI per 1,000 central lines $(2,223,650$ central-line days and 1,342 Candida isolates in NLCBIs) [2]. This shows that the pooled mean incidence density of Candida central-line-associated NLCBIs of 0.09 of our 682 German ICUs was several folds lower than that in United States ICUs. We cannot fully explain why the incidence densities in the United States and German ICUs were very different. Differences in healthcare systems should be taken into consideration and differences in the job description of medical staff might also contribute. Unlike in the United States, taking blood cultures cannot be delegated to nurses in Germany but have to be performed by physicians themselves. This might lead to underdetection of isolates that cause infections. The frequency of blood cultures per 1,000 patient days in German ICUs was considerably below the mean of all European ICUs ( 55 blood cultures per 1,000 bed days in German ICUs compared with 73 per 1,000 bed days in all European ICUs in 2004) [22].

In the United States, Candida was in 2008 the third leading pathogen responsible for NLBSIs, after coagulase-negative staphylococci and enterococci - ahead even of S. aureus and outnumbering all Gram-negative bacilli [2]. C. albicans and other Candida species account for $11.8 \%$ (each $5.9 \%$ ) to all central-line-associated bloodstream infections, according to data of the National Healthcare Safety Network [2].

Candida ranked second in the Extended Prevalence of Infection in the ICU (EPIC) II study, which included culture-positive infections in 1,265 ICUs in 75 countries in 2007 [23]. In contrast to our study, EPIC II focused on all infections (not only nosocomial); on all bloodstream infections (not only on primary bloodstream infections) and EPIC II was a prevalence study. Furthermore, the majority of all ICU infections in Western Europe were respiratory tract infections and only $14.8 \%$ were bloodstream infections. Only $8.2 \%$ of all bloodstream infections were caused by Candida if only monomicrobial bloodstream infections were analysed [9]. In our study, $6.5 \%$ were caused by Candida. Candida lies far behind the Gram-positive pathogens, coagulase-negative staphylococci, S. aureus and Enterococci.

Unfortunately, non-albicans Candida are not differentiated at species level in the Krankenhaus Infektions Surveillance System. However, the National Reference Centre for Systemic Mycoses published 2004-2005 data on the incidence and antifungal susceptibilities of Candida spp. in Germany: the majority of non-albicans Candida were C. glabrata (accounting for $44.9 \%$ ), followed by C. parapsilosis (22.5\%), C. tropicalis (15.2\%), C. kefyr (5.1\%) and C. krusei (3.9\%) [24]. 
In our study, non-albicans accounted for only a quarter of all Candida species. In other words, the frequency of C. albicans was $74 \%$, which was comparable with the $72 \%$ C. albicans in EPIC II in western European ICUs, whereas C. albicans was isolated less frequently in other geographical regions (e.g. only in $57 \%$ in Latin American ICUs) [9]. In a Swiss nationwide study, C. albicans remained the predominant Candida species recovered in $66 \%$ of all candidemias over a period of 10 years (1991-2000), which is also in accordance with our results [25]. Nonetheless, the predominance of Candida species differs geographically.

There are numerous studies demonstrating the shift from $C$. albicans to non-albicans species and describing the temporal and geographical influences on Candida species distribution $[3,4,26]$. Several factors may have contributed to these differences in species distribution and in frequency of isolation. They include attention to infection control, catheter-care guidelines and probably most importantly lack of drug pressure. The rise of non-albicans species is generally correlated with the therapeutic and prophylactic use of fluconazole [4]. Similar to antibiotic use, antimycotic use can

\section{TABLE 1}

Most frequently isolated pathogens in 5,970 monomicrobial primary nosocomial laboratory-confirmed bloodstream infections and related crude mortality in 682 intensive care units, Germany, 2006-2011

\begin{tabular}{|l|c|c|}
\hline Pathogen & $\begin{array}{c}\text { Number (\%) } \\
\text { of NLCBIs }\end{array}$ & $\begin{array}{c}\text { Number (\%) } \\
\text { of related } \\
\text { ICU deaths }\end{array}$ \\
\hline Coagulase-negative staphylococci & $2,128(35.6)$ & $339(15.9)$ \\
\hline Staphylococcus aureus & $895(15.0)$ & $150(16.8)$ \\
\hline MSSA & $568(9.5)$ & $80(14.1)$ \\
\hline MRSA & $327(5.5)$ & $70(21.4)$ \\
\hline Enterococcus spp. & $954(16)$ & $194(20.3)$ \\
\hline Candida spp. & $389(6.5)$ & $93(23.9)$ \\
\hline C. albicans & $288(4.8)$ & $63(21.9)$ \\
\hline non-albicans Candida & $101(1.7)$ & $30(29.7)$ \\
\hline Klebsiella spp. & $254(4.3)$ & $43(16.9)$ \\
\hline Pseudomonas aeruginosa & $159(2.7)$ & $39(24.5)$ \\
\hline Escherichia coli & $213(3.6)$ & $43(20.2)$ \\
\hline Enterobacter spp. & $183(3.1)$ & $27(14.8)$ \\
\hline Serratia spp. & $95(1.6)$ & $13(13.7)$ \\
\hline Acinetobacter spp. & $\mathbf{6 0 9 7 0 ( 1 )}$ & $14(23.3)$ \\
\hline Total & $\mathbf{1 0 7 0}(\mathbf{1 8 . 0})$ \\
\hline
\end{tabular}

ICU: intensive care unit; NLCBIs: nosocomial laboratoryconfirmed bloodstream infections; MRSA: meticillinresistant Staphylococcus aureus; MSSA: meticillin-sensitive Staphylococcus aureus.
TABLE 2

Cases and incidence of candidemia in Denmark, Finland, Germany and United States

\begin{tabular}{|l|c|c|c|c|}
\hline \multirow{2}{*}{$\begin{array}{l}\text { Data for the } \\
\text { year specified }\end{array}$} & $\begin{array}{c}\text { Denmark } \\
2009\end{array}$ & $\begin{array}{c}\text { Finland } \\
2007\end{array}$ & $\begin{array}{c}\text { Germany } \\
2008\end{array}$ & $\begin{array}{c}\text { United } \\
\text { States }^{\mathrm{d}} \\
2000\end{array}$ \\
\cline { 2 - 5 } & 470 & 161 & 3,712 & 16,500 \\
\hline Number of cases & 8.6 & 3.1 & 4.7 & 5.6 \\
\hline $\begin{array}{l}\text { Incidence } \\
\text { per 100,000 } \\
\text { population }\end{array}$ & & & & \\
\hline
\end{tabular}

Data from six departments of clinical microbiology, which serve a third of the Danish population [30].

b Data from the Finish National Infectious Disease Register, to which all clinical laboratories in Finland notify all fungal (and bacterial) isolates from blood [34].

Data from the German Institute for the Hospital Remuneration System (InEK) identified by the presence of the International classification of diseases, tenth revision (ICD-10) diagnosis code B37.7. [31].

d Data from the United States Agency for Healthcare Research and Quality identified by the presence of the International Classification of Diseases, Ninth Revision (ICD-9) diagnosis code $112.5[35]$

be hypothesised to be higher in the United States, for example, because of a more defensive type of medicine with more calculated or prophylactic anti-infective therapy because of the high risk of medical malpractice lawsuit [27]. This might influence endogenous colonisation. Although there are scarce comparative quantitative data on antifungal consumption, also within Europe, antifungal use, risk groups and healthcare budgets vary largely $[28,29]$. In Denmark, for example, over the last years from 2004 to 2009 , consumption increased by $140 \%$ [30].

Many studies state that candidemia is recognised as a leading cause of morbidity and mortality in severely ill patients and that crude (all-cause) mortality rates range between $20 \%$ and $60 \%$ [10]. We advocate differentiating between primary and secondary candidemia, because this has an impact on mortality rates, i.e. primary Candida bloodstream infections have lower mortality rates. It is of interest that non-albicans Candida species had the highest crude mortality rates (of almost 30\%), which underlines the importance of early and standardised detection of Candida species and drug-susceptibility testing.

Nationwide data for candidemia from the German Institute for the Hospital Remuneration System (all hospitals in the country, both primary and secondary bloodstream infections) revealed that the number of patients with candidemia was 3,712 cases 
- identified by presence of the International Statistical Classification of Diseases and Related Health Problems ICD-10 diagnosis code for candidemia - in 2008 in Germany (population of 82 million inhabitants) [31]. Use of these ICD-10 diagnosis codes seems unlikely to lead to the underestimation of the burden of candidemia, because they are required for reimbursement of hospital expenses. In the light of the results of our study, as well as remuneration data and increase in the consumption of antifungals, it seems reasonable to include antifungal use in antibiotic (or antimicrobial) stewardship programmes.

Our study has several strengths. The data result from a large network of 682 ICUs based on a comparatively long study period of six years. Surveillance data from the Krankenhaus Infektions Surveillance System are representative and validated $[32,33]$. Standard definitions were applied in all ICUs.

Several limitations of our study have to be taken into consideration: firstly, differences in the frequency of taking blood cultures across different ICUs. Furthermore, misclassification by the laboratories (e.g. non-albicans Candida for Saccharomyces) cannot be excluded. In addition, our data highlight only primary and not secondary NLCBIs. Secondary NLCBIs also play an important role in the ICU. The frequency of non-albicans bloodstream infections can also be influenced by the duration of incubation and subculture practices. A major limitation of the study is that non-albicans Candida species were not further classified. However, this is also the case in other surveillance systems on healthcare-associated infections, such as the United States National Healthcare Safety Network [2].

In conclusion, primary Candida NLCBIs showed no increase in the six-year study period in a network of 682 German ICUs. Primary Candida NLCBIs remain a rare event in spite of an upsurge in invasive procedures and therapies in an aging population and they should therefore not be overestimated.

\section{Acknowledgements}

We thank Ryan Plocher for his help in preparing the manuscript.

Financial support was provided by the German Ministry of Health

\section{Conflict of interest}

None declared.

\section{Authors' contributions}

EM conceived of the study, and wrote the manuscript. FS managed the data and performed the statistical analysis. CG and PG designed and coordinate the National Nosocomial Infection Surveillance System and helped to draft the manuscript. All authors read and approved the final manuscript.
References

1. Perlroth J, Choi B, Spellberg B. Nosocomial fungal infections: epidemiology, diagnosis, and treatment. Med Mycol. 2007;45(4):321-46. http://dx.doi. org/10.1080/13693780701218689 PMid: 17510856

2. Hidron AI, Edwards JR, Patel J, Horan TC, Sievert DM, Pollock DA, et al. NHSN annual update: antimicrobial-resistant pathogens associated with healthcare-associated infections: annual summary of data reported to the National Healthcare Safety Network at the Centers for Disease Control and Prevention, 2006-2007. Infect Control Hosp Epidemiol. 2008;29(11):996-1011. http://dx.doi.org/10.1086/591861 PMid: 18947320

3. Lass-Flörl C. The changing face of epidemiology of invasive fungal disease in Europe. Mycoses. 2009;52(3):197-205. http:// dx.doi.org/10.1111/j.1439-0507.2009.01691.x PMid:19391253

4. Pfaller MA, Diekema DJ. Epidemiology of invasive candidiasis: a persistent public health problem. Clin Microbiol Rev. 2007;20(1):133-63. http://dx.doi.org/10.1128/CMR.00029-06 PMid:17223626 PMCid:1797637

5. Pittet D, Monod M, Suter PM, Frenk E, Auckenthaler R. Candida colonization and subsequent infections in critically ill surgical patients. Ann Surg. 1994;220(6):751-8. http://dx.doi. org/10.1097/00000658-199412000-00008 PMid:7986142 PMCid:1234477

6. Leroy O, Gangneux JP, Montravers P, Mira JP, Gouin F, Sollet JP, et al. Epidemiology, management, and risk factors for death of invasive Candida infections in critical care: a multicenter, prospective, observational study in France (2005-2006). Crit Care Med. 2009;37(5):1612-8. http://dx.doi.org/10.1097/ CCM.obo13e31819efaco PMid:19325476

7. Renaud B, Brun-Buisson C; ICU-Bacteremia Study Group. Outcomes of primary and catheter-related bacteremia. A cohort and case-control study in critically ill patients. Am J Respir Crit Care Med. 2001;163(7):1584-90. http://dx.doi.org/10.1164/ ajrccm.163.7.9912080

PMid:11401878

8. Cisterna R, Ezpeleta G, Telleria O, Spanish Candidemia Surveillance Group. Nationwide sentinel surveillance of bloodstream Candida infections in 40 tertiary care hospitals in Spain. J Clin Microbiol. 2010;48(11):4200-6. http://dx.doi. org/10.1128/JCM.00920-10 PMid:20826636 PMCid:3020865

9. Kett DH, Azoulay E, Echeverria PM, Vincent JL; Extended Prevalence of Infection in ICU Study (EPIC II) Group of Investigators. Candida bloodstream infections in intensive care units: analysis of the extended prevalence of infection in intensive care unit study. Crit Care Med. 2011;39(4):66570. http://dx.doi.org/10.1097/CCM.ob013e318206c1ca PMid:21169817

10. Méan M, Marchetti O, Calandra T. Bench-to-bedside review: Candida infections in the intensive care unit. Crit Care. 2008;12(1):204.

http://dx.doi.org/10.1186/cc6212 PMid:18279532 PMCid:2374590

11. Spiliopoulou A, Dimitriou G, Jelastopulu E, Giannakopoulos I, Anastassiou ED, Christofidou M. Neonatal intensive care unit candidemia: epidemiology, risk factors, outcome, and critical review of published case series. Mycopathologia. 2012;173(4):219-28.

http://dx.doi.org/10.1007/s11046-011-9498-3 PMid:22076411

12. Diekema DJ, Pfaller MA. Nosocomial candidemia: an ounce of prevention is better than a pound of cure. Infect Control Hosp Epidemiol. 2004;25(8):624-6. http://dx.doi. org/10.1086/502451 PMid:15357151

13. BCC Research. Antifungal drugs:technologies and global market. Wellesley, MA: BCC Research; 2010. [Accessed 21 May 2013]. Available from: http://www.bccresearch.com/report/ PHM029C.html

14. Bundesministerium der Justiz. Gesetz zur Verhütung und Bekämpfung von Infektionskrankheiten beim Menschen (Infektionsschutzgesetz - IfSG). [Infection Control and Prevention Act]. Berlin: Bundesministerium der Justiz; 2001 (updated 2012). German. [Accessed 21 May 2013]. Available from: http://www.gesetze-im-internet.de/bundesrecht/ifsg/ gesamt.pdf

15. Gastmeier P, Sohr D, Schwab F, Behnke M, Zuschneid I, Brandt $C$, et al. Ten years of KISS: the most important requirements for success. J Hosp Infect. 2008;70 Suppl 1:11-6. http://dx.doi. org/10.1016/S0195-6701(08)60005-5

16. Robert Koch Institute (RKI). Definitionen nosokomialer Infektionen (CDC-Definitionen). [Definitions of nosocomial infections (CDC definitions)]. Berlin: RKI; 2011. German. [Accessed 21 May 2013]. Available from: http://www. nrz-hygiene.de/surveillance/kiss/cdc-definitionen/ a43ef62e/591/733/ 
17. Edwards JR, Peterson KD, Mu Y, Banerjee S, Allen-Bridson K, Morrell G, et al. National Healthcare Safety Network (NHSN) report: data summary for 2006 through 2008 , issued December 2009. Am J Infect Control. 2009;37(10):783-805. http://dx.doi.org/10.1016/j.ajic.2009.10.001 PMid:20004811

18. Institut für das Entgeltsystem im Krankenhaus [German Institute for the Hospital Remuneration System] (InKE). Systemjahr 2010 bzw. Datenjahr 2008. [2010 Archive system year 2010 and data year 2008, respectively]. Siegburg: InEK. German. [Accessed 21 May 2013]. Available from: http:// www.g-drg.de/cms/Archiv\#sj2010dj2008

19. Federal Government of Germany. Gesundheitsberichterstattung des Bundes. [Health report of the Federal Government of Germany]. Berlin: Federal Government of Germany; 2008. German. [Accessed 21 May 2013]. Available from: http://www.gbe-bund.de/oowa921-install/servlet/oowa/ aw92/dboowasys921.xwdevkit/xwd_init?gbe.isgbetol/ xs_start_neu $/ \& p$ aid $=3 \& p \_a i d=27078510 \&$ nummer $=838 \& p$ sprache $=$ D\&p_indsp $=-\&$ p_aid $=87219284$

20. European Centre for Disease Prevention and Control (ECDC). Annual epidemiological report on communicable diseases in Europe 2010. Stockholm: ECDC; 2010.Available from: http:// ecdc.europa.eu/en/publications/publications/1011_sur annual epidemiological_report_on_communicable_diseases_ in_europe.pdf

21. Trick WE, Fridkin SK, Edwards JR, Hajjeh RA, Gaynes RP; National Nosocomial Infections Surveillance System Hospitals. Secular trend of hospital-acquired candidemia among intensive care unit patients in the United States during 1989-1999. Clin Infect Dis. 2002;35(5):627-30. http://dx.doi. org/10.1086/342300 PMid:12173140

22. Hansen S, Schwab F, Behnke M, Carsauw H, Heczko P, Klavs I, et al. National influences on catheter-associated bloodstream infection rates: practices among national surveillance networks participating in the European HELICS project. J Hosp Infect. 2009;71(1):66-73. http://dx.doi.org/10.1016/j. jhin.2008.07.014 PMid:18799236

23. Vincent JL, Rello J, Marshall J, Silva E, Anzueto A, Martin CD, et al. International study of the prevalence and outcomes of infection in intensive care units. JAMA. 2009;302(21):2323-9. Epub 2009/12/03.

24. Borg-von Zepelin M, Kunz L, Ruchel R, Reichard U, Weig $M$, Gross U. Epidemiology and antifungal susceptibilities of Candida spp. to six antifungal agents: results from a surveillance study on fungaemia in Germany from July 2004 to August 2005. J Antimicrob Chemother. 2007;60(2):424-8. http://dx.doi.org/10.1093/jac/dkm145 PMid:17562683

25. Marchetti O, Bille J, Fluckiger U, Eggimann P, Ruef C, Garbino J, et al. Epidemiology of candidemia in Swiss tertiary care hospitals: secular trends, 1991-2000. Clin Infect Dis. 2004;38(3):311-20. http://dx.doi.org/10.1086/380637 PMid:14727199

26. Bouza E, Mu-oz P. Epidemiology of candidemia in intensive care units. Int J Antimicrob Agents. 2008;32 Suppl 2:S87-91. http://dx.doi.org/10.1016/S0924-8579(08)70006-2

27. Harbarth S, Albrich W, Goldmann DA, Huebner J. Control of multiply resistant cocci: do international comparisons help? Lancet Infect Dis. 2001;1(4):251-61. http://dx.doi.org/10.1016/ S1473-3099(01)00120-7

28. Edmond MB, Wallace SE, McClish DK, Pfaller MA, Jones RN, Wenzel RP. Nosocomial bloodstream infections in United States hospitals: a three-year analysis. Clin Infect Dis. 1999;29(2):239-44. http://dx.doi.org/10.1086/520192 PMid:10476719

29. Spiliopoulou A, Vamvakopoulou S, Bartzavali C, Dimitracopoulos G, Anastassiou ED, Christofidou M. Elevenyear retrospective survey of candidaemia in a university hospital in southwestern Greece. Clin Microbiol Infect. 2010;16(9):1378-81. http://dx.doi.org/10.1111/j.14690691.2010.03193.x PMid:20156217

30. Arendrup MC, Bruun B, Christensen JJ, Fuursted K, Johansen HK, Kjaeldgaard P, et al. National surveillance of fungemia in Denmark (2004 to 2009). J Clin Microbiol.49(1):325-34.

31. Institut für das Entgeltsystem im Krankenhaus [German Institute for the Hospital Remuneration System] (InEK). Auswertungen im Rahmen der Begleitforschung für das Datenjahr 2008. [Analysis for the data year 2008 in the frame of accompanying research]. Siegburg: InEK. German. [Accessed 21 May 2013]. Available from: http://www.g-drg.de/cms/ content/view/full/2571

32. Zuschneid I, Geffers C, Sohr D, Kohlhase C, Schumacher M, Ruden $\mathrm{H}$, et al. Validation of surveillance in the intensive care unit component of the German nosocomial infections surveillance system. Infect Control Hosp Epidemiol. 2007;28(4):496-9.

http://dx.doi.org/10.1086/512631 PMid:17385161
33. Zuschneid I, Rucker G, Schoop R, Beyersmann J, Schumacher M, Geffers C, et al. Representativeness of the surveillance data in the intensive care unit component of the German nosocomial infections surveillance system. Infect Control Hosp Epidemiol. 2010;31(9):934-8. http://dx.doi.org/10.1086/655462 PMid:20662616

34. Poikonen E, Lyytikäinen O, Anttila VJ, Koivula I, Lumio J, Kotilainen P, et al. Secular trend in candidemia and the use of fluconazole in Finland, 2004-2007. BMC Inf Dis.2010; 10(1):312. http://dx.doi.org/10.1186/1471-2334-10-312 PMid:21029444 PMCid:2988049

35. Zilberberg MD, Shorr AF, Kollef MH. Secular trends in candidemia-related hospitalization in the United States, 20002005. Infect Control Hosp Epidemiol. 2008;29(10):978-80. http://dx.doi.org/10.1086/591033 PMid:18715153 